\title{
Effect of Decreasing Water Levels on the Spawning Rate and Egg Count of Female Crayfish Procambarus (Austrocambarus) llamasi (Villalobos, 1955)
}

\section{Carmona-Osalde Claudia', Puerto-Novelo Enrique ${ }^{2}$ and Miguel Rodriguez-Serna ${ }^{1 *}$}

${ }^{1}$ National Autonomous University of Mexico (UNAM), Faculty of Science, Multidisciplinary Teaching and Research Unit, Sisal, Aquaculture Biotechnology Area, Mexico ${ }^{2}$ Center for Research and Advanced Studies of the IPN (CINVESTAV-IPN) Unit MÉRIDA, Mexico

\begin{abstract}
Three different water levels were assessed to establish their role in Procambarus llamasi spawning synchronization. A total of 132 crayfish were used for this assay, 120 were female and 12 were male $\mathrm{Fl}$ (reproductive male stage), with an average initial size of $45 \mathrm{~mm}$ total length and $2.5 \mathrm{~g}$ in weight. $P$. Ilamasi were produced under controlled conditions at CINVESTAV-Merida, Yucatan, Mexico. The experimental system consisted of 12 plastic tanks of $0.60 \times 0.34 \times 0.28 \mathrm{~m}$, equipped with water recirculation, biological filters, individual PVC shelters, a constant water temperature of $26^{\circ} \mathrm{C}$ and total darkness. Decreasing water levels in the crayfish tanks showed an important negative effect of this factor on most of the biological parameters measured, including the spawning rate and the number of eggs spawned by females. Spawning female sizes in low water levels were smaller and with fewer eggs than in the other levels. These results revealed an important relationship between water level and spawning rate for P. llamasi.
\end{abstract}

Keywords: Water levels; Spawning; Eggs numbers; Procambarus llamasi

\section{Introduction}

Increasing interest in crayfish culture has lead to develop research on the role that environmental factors play in reproduction. Most attempts in controlling breeding have been made by assessing different environmental factors, mainly, temperature and photoperiod regimens [1-3].

Environmental factors may affect the reproductive performance of crayfish in different ways. Reproduction comprises a series of physiological processes from gonadogenesis to spawning. Synchronization of spawning is critical from a productive point of view, as it offers two main advantages for hatchery operations. First, it reduces the required number of broodstock, as non-productive females would not be maintained in the system. Second, it allows having juvenile crayfish of the same age and size at the same time all year long.

Recent studies have found different spawning results among crayfish species. In some, like Cherax quadricarinatus (von Martens), Procambarus clarkii (Girard), and Orconectes virilis (Hagen), spawning was improved by increasing temperature and photoperiod under laboratory conditions [4-6]. In other species, such as Procambarus (Autrocambarus) and llamasi (Villalobos), temperature improved only gonad maturation, and there was not noted any positive effect on spawning (Figure 1).

According to [7] and Collins and Mitchell, synchronic spawning cannot be achieved using temperature, photoperiod, or density management. For P. llamasi and C. quadricarinatus, the best spawning rate reported under control conditions is less than $50 \%$.

Some efforts have been made to improve spawning synchronization, but to date, it is not clear which environmental factor serves as trigger cue in P. llamasi. In other aquatic organisms, water level manipulation is used to control spawning by decreasing water depth [8,9]. In crayfish, water level fluctuation has been identified as an important and critical factor in inducing reproductive adaptations [10-13]. An example of this reproductive cycle adaptation in relation to the hydrological regime is found in P. clarkii. According to P. clarkii is capable of developing different reproductive strategies directly related to the hydroperiod of the region.

In an attempt to better understand the possible role of water level in the spawning response of $P$. llamasi, we performed a study in which three different water depths were assessed on the spawning rate and

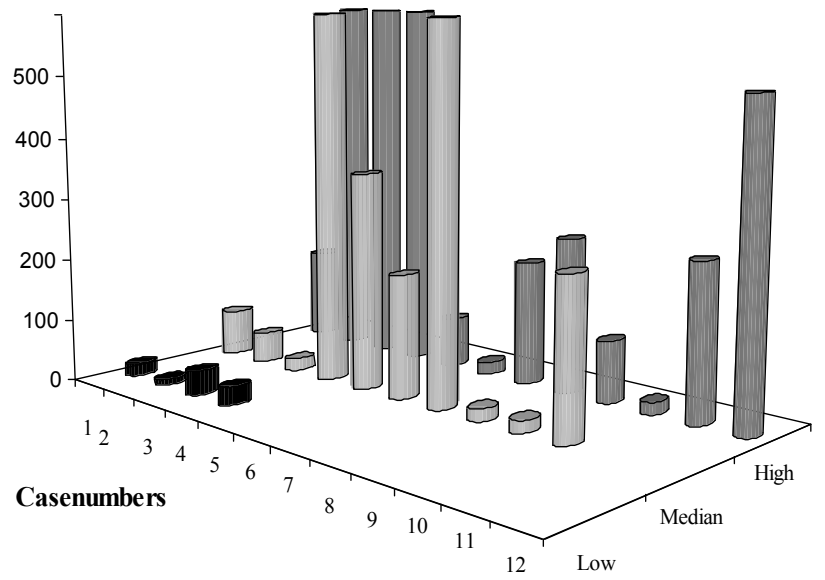

Figure 1: Eggs numberper female of Procambarus llamasi at different water levels.

*Corresponding author: Miguel Rodriguez-Serna, National Autonomous University of Mexico (UNAM), Faculty of Science, Multidisciplinary Teaching and Research Unit, Sisal, Aquaculture Biotechnology Area, Mexico, Tel: 988-91201-47; E-mail:mrserna66@gmail.com.

Received February 06, 2015; Accepted February 25, 2015; Published March 25 2015

Citation: Claudia CO, Enrique PN, Rodriguez-Serna M (2015) Effect of Decreasing Water Levels on the Spawning Rate and Egg Count of Female Crayfish Procambarus (Austrocambarus) Ilamasi (Villalobos, 1955). J Aquac Res Development 6: 331. doi:10.4172/2155-9546.1000331

Copyright: (c) 2015 Claudia CO, et al. This is an open-access article distributed under the terms of the Creative Commons Attribution License, which permits unrestricted use, distribution, and reproduction in any medium, provided the original author and source are credited. 
Citation: Claudia CO, Enrique PN, Rodriguez-Serna M (2015) Effect of Decreasing Water Levels on the Spawning Rate and Egg Count of Female Crayfish Procambarus (Austrocambarus) Ilamasi (Villalobos, 1955). J Aquac Res Development 6: 331. doi:10.4172/2155-9546.1000331

Page 2 of 4

number of eggs per spawned female of $P$. llamasi in order to determine the possible effect of water levels on spawning synchronization.

\section{Materials and Methods}

A total of 132 P. llamasi were used for this study. 120 were female and 12 were male FI (reproductive male) with an average initial size of $45 \mathrm{~mm}$ total length and a weight of $2.5 \mathrm{~g}$. P. llamasi were produced under controlled conditions at CINVESTAV- Merida, Yucatan, Mexico. The experimental system consisted of twelve plastic tanks of $0.60 \times 0.34 \times 0.28 \mathrm{~m}$, provided with water recirculation, biological filters, individual PVC shelters, constant water temperature of $26^{\circ} \mathrm{C}$ and total darkness. Ten females and one reproductive male FI were placed in each plastic tank.

Three different water levels were tested, in quadruplicate, on the spawning rate and the number of eggs per female: a low level of $0.03 \mathrm{~m}$; a medium level of $0.15 \mathrm{~m}$, and a high level of $0.25 \mathrm{~m}$.

During the 120 days of the experiment, animals were fed with a commercial shrimp diet (Purina: $35 \%$ protein, $6 \%$ lipids) once a day ad libitum. All tanks were checked every day for dead animals and spawned females. Spawned females were removed from the system and eggs were counted. To maintain the same density proportion, removed females were replaced with new ones.

Mortality and spawning rate were recorded throughout the experimental period.

Growth was estimated as a function of weight and total length, with measurements taken every 15 days. Specific Growth Rate (SGR) was estimated according to Goolish and Adelman (1984), as well as the following parameters:

Survival [\%=100 ((Initial Number-Final Number)/Total Number) $]$ Weigh Gain $=[\%=100(($ Final Weight-Initial Weight $) /$ Initial Weight $)]$ Length $=[\%=100$ ((Final Length-Initial Weight)/Initial Weight) $]$ SGR $(\% /$ day $)=100($ loge Final Weight-loge Initial Weight $) /$ Time $)$

Survival, growth, spawning and egg count/female results were compared using a one-way variance analysis (ANOVA) with a $95 \%$ significance level. The difference between means was determined with a Tuckey Multiple Ranges test [14] and all statistical evaluation was performed using Statgraphics ver. 4.1software. Values were arcsine transformed when necessary.

\section{Results}

\section{Survival}

Survival rate of experimental animals showed statistical differences $(\mathrm{p}<0.05)$ among the three water levels assessed (Table 1). Low water levels yielded the lowest survival rate with $77 \%$, while medium water levels yielded the highest with $98 \%$.

According to the present results, decreasing water levels had a negative effect on crayfish survival, with an increase in crayfish mortality as water depth was reduced.

\section{Growth}

Table 1 shows the obtained growth parameters. There was a statistical difference in final weight between low and high water levels, with $3.45 \mathrm{~g}$ for the former and 5.19 for the latter. Animals in lower water levels experienced a reduction in growth as compared to animals in greater depths. The Specific Growth Rate was statistically similar between low and medium levels, but not between these and the highest

\begin{tabular}{|l|c|c|c|c|}
\hline Parameter & Low & Median & High & ISE \\
\hline Initial number & 40 & 40 & 40 & \\
\hline $\begin{array}{l}\text { Final number } \\
\text { Survival (\%) }\end{array}$ & 31 & 39 & 36 & 1.5618 \\
\hline Initial Length & $77^{\mathrm{a}}$ & $98^{\mathrm{c}}$ & $90^{\mathrm{b}}$ & \\
\hline Final Length & $48.6^{\mathrm{a}}$ & $46.6^{\mathrm{a}}$ & $42.25^{\mathrm{a}}$ & 1.7538 \\
\hline Initial Weight (g) & $61.75^{\mathrm{a}}$ & $62.55^{\mathrm{a}}$ & $64.92^{\mathrm{a}}$ & 1.6494 \\
\hline Final Weight (g) & $2.96^{\mathrm{a}}$ & $2.61^{\mathrm{a}}$ & $2.0^{\mathrm{a}}$ & 0.1572 \\
\hline Weight gain (g) & $6.42^{\mathrm{a}}$ & $6.89^{\mathrm{a}}$ & $7.11^{\mathrm{a}}$ & 0.4212 \\
\hline Weight gain (\%) & $3.45^{\mathrm{a}}$ & $4.27^{\mathrm{ab}}$ & $5.19^{\mathrm{b}}$ & 0.4165 \\
\hline Specific Growth Rate (\%/day) & $133.74^{\mathrm{a}}$ & $185.19^{\mathrm{a}}$ & $343.13^{\mathrm{b}}$ & 29.233 \\
\hline Feed intake (g) & $0.825^{\mathrm{a}}$ & $1.069^{\mathrm{a}}$ & $1.527^{\mathrm{b}}$ & 0.0928 \\
\hline Feed Conversion Ratio & $2.90^{\mathrm{a}}$ & $2.87^{\mathrm{a}}$ & $2.90^{\mathrm{a}}$ & 0.1414 \\
\hline Female spawning (\%) & $1.8^{\mathrm{a}}$ & $1.11^{\mathrm{ab}}$ & $1.0^{\mathrm{b}}$ & 0.3295 \\
\hline Eggs number per female & $13.33^{\mathrm{a}}$ & $25.6^{\mathrm{b}}$ & $34.3^{\mathrm{c}}$ & 1.33 \\
\hline Spawned female size (mm) & $56^{\mathrm{a}}$ & $218.5^{\mathrm{b}}$ & $280.8^{\mathrm{b}}$ & 25.9 \\
\hline & $57^{\mathrm{ab}}$ & $62^{\mathrm{b}}$ & 0.3623 \\
\hline
\end{tabular}

*Numbers with the same superscript are not statistically different $(p>0.05)$.

Table 1: ANOVA results for the effect of water levels on spawning and egg count in Procambarus llamasi.

water level. The SGR of crayfish under low water level conditions was almost half of that achieved in high water level conditions.

\section{Food efficiency}

Food efficiency parameters are shown in Table 1. Feed intake results were very similar among the three water level treatments, with values reported between 2.87 to $2.90 \mathrm{~g}$.

Feed Conversion Ratio showed efficiency values in all treatments with statistical differences between animals in the low water level treatment and the high water level treatment.

\section{Spawning}

Spawning results are shown in Table 1. An important effect of water level was observed on the spawning rate of crayfish among the treatments. Statistical differences were found among low, medium, and high water levels, with the lowest percentage (13.33\%) in low water conditions and the highest (34.3\%) in high water levels.

Spawning was found to be directly related to water depth. Spawned females in the lowest water level tanks had smaller sizes than those spawned in the other two treatments.

\section{Egg number}

The number of eggs spawned per female is presented in Table 1. As with the spawning rate, water level had an important effect on this parameter. Statistical differences were found among water levels with the best results in high water level treatments.

\section{Discussion}

Important efforts have been made to manipulate environmental factors in controlling crustacean reproduction. Many studies asses the modulator effect of light and temperature in the reproductive cycle of marine and freshwater species, but the truth is that maturation and, particularly, spawning have not been successful in achieving aquaculture goals with changes in photoperiod and/or temperature regimes. 
If we take a look at penaeid shrimp maturation and spawning results, positive results have been reported with long photoperiods and temperatures above $25^{\circ} \mathrm{C}$ [15-17] but these never promoted faster maturation and better spawning rates than eyestalk ablation [18]. In lobsters, the effects of photoperiod and temperature are so variable that no independent response could be identified. Ovarian development required combined conditions of these factors. Under a long photoperiod (14 L), ovarian development progressed slowly with temperature and the developmental rate increased as temperature increased. On the other hand, ovarian development under a short photoperiod $(10 \mathrm{~L})$ depended on temperature. Ovarian development at $13^{\circ} \mathrm{C}$ progressed similar to that of a long photoperiod, whereas it was prevented or considerably delayed at $19^{\circ}$ and $25^{\circ} \mathrm{C}$. In Panulirus japonicus (von Siebold), both temperature and photoperiod are important factors in controlling ovarian development, but not in spawning [6].

For crayfish, controversial results have been obtained using different photoperiods and temperatures [4-6]. Numerous studies have analyzed the effect of either temperature or photoperiod separately, or in conjunction. When assessed separately, some authors argue that both factors often interact in complex ways (e.g. when both are increased they often affect gonad maturation and spawning synergistically), and may produce different effects depending on the species $[19,20]$.

Several attempts have been made to induce off-season spawning in crayfish from the northern hemisphere and temperate climate by manipulating both temperature and photoperiod with temperature as the predominate cue for egg laying [21] found that increasing temperature by $5^{\circ} \mathrm{C}$ triggered egg laying in Astacus astacus L., whereas photoperiod played only a secondary role throughout the course of two simulated cycles in one full year. According to high temperature following several cold months accelerated egg laying compared to that obtained in natural populations, whereas exposure to a long photoperiod had no effect in Orconectes limosus (Rafinesque). In Orconectes virilis, raising temperature slightly higher than that in the natural environment following several months of low temperature accelerated egg laying by 5 to 7 weeks earlier than crayfish remaining outdoors. In this case, the photoperiod was not a triggering factor, unlike the increase in temperature.

In P. llamasi, previous results reported no effect of light on gonad maturation or spawning. No differences in the reproductive performance were observed between animals maintained under complete darkness and those in natural photoperiod. In contrast, constant temperatures in the same species showed an important effect on gonad maturation, but not on the spawning rate.

P. llamasi gonad maturation is mostly affected by temperature. Unfortunately, the effect of this factor has not been successfully proven on crayfish spawning and to date it is not clear which environmental factor or factors may serve as a key cue for triggering this process [22]. In general terms, temperature alone improves maturation, but not spawning; whereas the effect of light has not been clearly established.

From an aquaculture point of view, synchronization of spawning could allow for some important advantages in broodstock areas and management. Differences in crayfish spawning rates have been reported between natural populations and laboratory conditions, with higher spawning rates and synchronization under natural conditions.

According to [20] the spawning rate of natural populations in Doñona, Spain, of P. clarkii, is between $75 \%$ and $93 \%$. In contrast, C. quadricarinatus and P. llamasi maintained under experimental conditions resulted in less than $50 \%$ of spawned females with no synchronization [23].

In some aquatic organisms, decreasing the water level has a spawning-promoting effect. Water level is one of the most common factors that successfully induce spawning in the culturing practices of some fish and water snail species. Pomacea urceus (Müller) snails mate at the end of the rainy season and burrow into the substratum as the water levels of the rivers and swamps decrease.

Snails, therefore, use a decrease in water level as the cue for spawning. A decrease in water level under controlled conditions triggers mating and spawning. In tanks without water level fluctuations, no mating or spawning took place. This method is inexpensive and reliable, and has important practical applications for snail culture.

In the present study, water level was decreased with the intent to induce spawning in crayfish P. llamasi. Water level, however, not only showed a negative influence on the spawning rate of crayfish, but also in the growth and survival of the species. Fecundity decreased drastically in low water treatments as compared to the other two treatments. Mean fecundity reported by [13] for P. llamasi, under laboratory conditions, is of 311 eggs/female, with a minimum of 200 and a maximum of 700 . In the medium and high level treatments, fecundity and female average size improved. It is possible that animals maintained in low water levels suffer from stress, which is reflected in the limited development of the parameters studied.

Very little is known about the effect of water level and crayfish reproduction. There are no previous results on the effect of water level and crayfish spawning under laboratory conditions, but natural population sites, where crayfish are found to be present, had a water depth of $20 \mathrm{~cm}$ and generally no crayfish are found in those with $15 \mathrm{~cm}$ or less of water depth [24]. The effect of water level on the reproductive strategies under natural conditions has been reported for P. clarkii in Spain by [12]. P. clarkii, adjusts its reproductive cycle to the annual and inter-annual hydrologic fluctuations of water levels at the Doñona Park, Spain, with three different strategies. Populations living in freshwater with a temporal seasonal system and a short hydroperiod of 3-4 months reproduce only once per year, when temperature is approximately $20^{\circ} \mathrm{C}$ and water depth is approximately $30 \mathrm{~cm}$ [25].

Populations living in ecosystems with a long hydroperiod (greater than 6 months) have two reproductive periods. Thirdly, crayfish living in permanent ecosystems show a large reproductive period from fall to spring.

In this sense, the Yucatan Peninsula has three main seasons: rainy, dry, and "nortes" (northerlies). During the rainy and north-winds season (May-December), most of the land is flooded. When the dry season arrives, water bodies begin to reduce until only some shallow waters remain and these maintain most of the adult population.

Under this dry condition, in which high individual aggregation and temperatures are combined, females probably mature but do not spawn. Using a different strategy, they wait until the water level rises. This could allow for young crayfish to maximize the utilization of the flooded areas.

The reproductive strategy of this species may be based on the presence of water for the new generations. The dry season lasts from four to five months, a very long time to withstand temperatures above $30^{\circ} \mathrm{C}$ and high desiccation. Increased water levels may be a more important signal for P. llamasi to ensure survival of the offspring in 
Citation: Claudia CO, Enrique PN, Rodriguez-Serna M (2015) Effect of Decreasing Water Levels on the Spawning Rate and Egg Count of Female Crayfish Procambarus (Austrocambarus) llamasi (Villalobos, 1955). J Aquac Res Development 6: 331. doi:10.4172/2155-9546.1000331

places where water accumulation is very difficult because of the karstic nature of its soil.

In summary, decreasing water levels in crayfish tanks showed an important negative effect on most of the biological parameters measured, including spawning rate and the number of eggs spawned by females. Spawned female sizes in low water levels were smaller and produced fewer eggs than those in the other levels. It is interesting, however, to have found reproduction under this water level condition.

\section{Acknowledgment}

To program PAPIIT-UNAM for the financial support by project IN203906-3: Adaptation of the crayfish Procambarus llamasi to contrasting environments in the Yucatan Peninsula

\section{References}

1. Yeh HS, Rouse BD (1995) Effects of water temperature, density and sex ratio on the spawning rate of red claw crayfish Cherax quadricarinatus (von Martens). Journal of the World Aquaculture Society 26: 160-164.

2. Carmona-Osalde C, Rodríguez-Serna M, Olvera-Novoa MA (2002) The influence of the absence of light on the onset of first maturity and egg laying of the crayfish Procambarus (Austrocambarus) llamasi (Villalobos, 1955). Aquaculture 212: 289-298.

3. Carmona-Osalde C, Rodríguez-Serna M, Olvera-NovoaMA, Gutierrez-Yurrita PJ (2004) Gondadal development, spawning, growth and survival of the crayfish Procambarus llamasi at three different water temperatures. Aquaculture 232 : 305-316.

4. Portelance B, Dubé $P$ (1995) Temperature and photoperiod effects on ovarian maturation, ovarian growth and egg-laying of Orconectes virilis. Freshwater Crayfish 8: 321-330.

5. Provenzano AJ, Handwerker TS (1995) Effects of photoperiod on spawning of red swamp crayfish, Procambarus clarkii, at elevated temperature. Freshwater Crayfish 8: 311-320.

6. Matsuda H, Takenouchi T, Takashi Y (2002) Effects of photoperiod and temperature on ovarian development and spawning of the Japanese spiny lobster Panulirus japonicus. Aquaculture 205: 385-398.

7. Carmona-Osalde C, Rodríguez-Serna M, Olvera-NovoaMA, Gutierrez-Yurrita PJ (2004) Effect of density and sex ratio on gonad development and spawning in the crayfish Procambarus llamasi. Aquaculture 236: 331-339.

8. Kungvankij P (1988) Guide to marine finfish hatchery management. F.A.O. Rome.

9. Ramanrine IW (2003) Induction of spawning and artificial incubation of eggs in the edible snail Pomacea urceus (Muller). Aquaculture 215: 163-166.
10. Huner JV (1988) Procambarus in North America and elsewhere.

11. Momot WT (1993) The role of exploitation in altering the processes regulating crayfish populations. Freshwater Crayfish 9: 101-117.

12. Gutiérrez-Yurrita PJ (1997) he ecological role of crayfish (Procambarus clarkii) in aquatic ecosystems Doñona National Park. An ecophysiological perspective and Bioenergetics.

13. Rodríguez-Serna M (1999) Biology and systematics Cambáridos southeastern Mexico and its potential use in aquaculture.

14. Zar JH (1996) Biostatistical analysis.

15. Crocos PJ, Kerr JD (1986) Factors affecting induction of maturation and spawning of the tiger prawn Penaeus esculentus (Haswell), under laboratory conditions. Aquaculture 58: 203-214

16. Brown A, McVey JP, Middleditch BS, Lawrence AL (1979) The maturation of white shrimp (Penaeus setiferus) in captivity. World Mariculture Society 10 435-444.

17. Cripe GM (1994) Induction of maturation and spawning of pink shrimp, Penaeus duarorum by changing water temperature, and survival and growth of young Aquaculture 128: 255-260.

18. Aktas, M., Kumlu M, Eroldogan OT (2003) Off-season maturation and spawning of Penaeus semisulcatus by eyestalk ablation and/or temperature-photoperiod regimes. Aquaculture 228: 361-370.

19. Dube P, Portelance B (1992) Temperature and photoperiod effects of ovarian maturation and egg laying of the crayfish Orconectes limosus. Aquaculture 102: $161-168$

20. Gutiérrez-Yurrita PJ, Montes C (1999) Bioenergetics and phenology of reproduction of the introduced red swamp crayfish, Procambarus clarkii, in DonÄ ana National Park, Spain, and implications for species management. Feshwater Biology 42: 561-574.

21. Westin L, Gydemo RG (1986) Influence of light and temperature on reproduction and moulting frequency of the crayfish, Astacus astacus (L.). Aquaculture 52 43-50.

22. Karplus I, Gideon H, Barki A (2003) Shifting the natural spring-summer breeding season of the Australian freshwater crayfish Cherax quadricarinatus into the winter by environmental manipulations. Aquaculture 220: 277-286.

23. Barki, A, Levi T, Hulata G, Karplus I (1997) Annual cycle of spawning and molting in the red-claw crayfish, Cherax quadricarinatus, under laboratory conditions. Aquaculture 157: 239-249.

24. Jordan CF (1996) Spatial ecology of decapods and fishes in a northern everglades wetland mosaic.

25. Goolish EM, Adelman IB (1984) Effects of ration size and temperature on the growth of juvenile common carp Cyprinus carpio. Aquaculture 36: 27-35. 